\title{
Prediction of Length of Hospital Stay in Preterm Infants a Case-Based Reasoning View
}

\author{
Ana Coimbra, Henrique Vicente, António Abelha, M. Filipe Santos, \\ José Machado, João Neves and José Neves
}

\begin{abstract}
The length of stay of preterm infants in a neonatology service has become an issue of a growing concern, namely considering, on the one hand, the mothers and infants health conditions and, on the other hand, the scarce healthcare facilities own resources. Thus, a pro-active strategy for problem solving has to be put in place, either to improve the quality-of-service provided or to reduce the inherent financial costs. Therefore, this work will focus on the development of a diagnosis decision support system in terms of a formal agenda built on a Logic Programming approach to knowledge representation and reasoning, complemented with a case-based problem solving methodology to computing, that caters for the handling of incomplete, unknown, or even contradictory information. The proposed model has been quite accurate in predicting the length of stay (overall accuracy of $84.9 \%$ ) and by reducing the computational time with values around $21.3 \%$.
\end{abstract}

\footnotetext{
A. Coimbra

Departamento de Informática, Universidade do Minho, Braga, Portugal e-mail: cecilia.coimbra@hotmail.com

H. Vicente

Departamento de Química, Escola de Ciências e Tecnologia

Universidade de Évora, Évora, Portugal

e-mail: hvicente@uevora.pt

H. Vicente - A. Abelha - M. Filipe Santos · J. Machado · J. Neves (

Centro Algoritmi, Universidade do Minho, Braga, Portugal

e-mail: jneves@di.uminho.pt
}
A. Abelha
e-mail: abelha@di.uminho.pt
M. Filipe Santos
e-mail: mfs@dsi.uminho.pt
J. Machado
e-mail: jmac@di.uminho.pt

J. Neves

Drs. Nicolas \& Asp, Dubai, United Arab Emirates

e-mail: joaocpneves@gmail.com

I. Czarnowski et al. (eds.), Intelligent Decision Technologies 2016,

Smart Innovation, Systems and Technologies 56,

DOI 10.1007/978-3-319-39630-9_10 
Keywords Preterm infants - Length of stay - Neonatology • Knowledge representation and reasoning • Logic programming • Case-based reasoning 